\title{
Material Invagination
}

National Cancer Institute

\section{Source}

National Cancer Institute. Material Invagination. NCI Thesaurus. Code C63063.

Problem associated with an undesired material change in shape, characterized by the infolding of one part within another part of a structure. 